\title{
Are risk factors for conversion to NIDDM similar in high and low risk populations?
}

\author{
S.M. H affner, H . M iettinen, M. P. Stern \\ D epartment of M edicine, D ivision of Clinical E pidemiology, U niversity of Texas H ealth Science Center, San A ntonio, Texas, U SA
}

Summary Mexican A mericans have an increased risk of non-insulin-dependent diabetes mellitus (NIDDM) relative to non-H ispanic whites which is only partially explained by their excess overall obesity and unfavourable body fat distribution. N on-diabetic Mexican A mericans have hyperinsulinaemia and insulin resistance relative to non- $\mathrm{H}$ ispanic whites. We therefore hypothesized that the insulin resistance might be a more important predictor of NIDDM in high-risk populations characterized by obesity and insulin resistance, while compromised insulin secretion might be a more important risk factor for NIDDM in low-risk populations. We assessed the ability of ethnicity (M exican A merican vs non-H ispanic white), age, overall adiposity (body mass index $[B M I])$, unfavourable body fat distribution (as assessed by waist-to-hip ratio [WHR]), glucose tolerance (impaired glucose tolerance vs normal glucose tolerance), fasting insulin and compromised insulin secretion (as assessed by increment in insulin to the increment in glucose over the first $30 \mathrm{~min}$ of an oral glucose tolerance test $\left.\left(\Delta \mathrm{I}_{30} / \Delta \mathrm{G}_{30}\right)\right)$ to predict future NIDD M . In the 8-year follow-up of the San A ntonio Heart Study, N ID D M developed in 11.7\% (107/914) of M exican A mericans and in $5.0 \%$ (18/362) of non$\mathrm{H}$ ispanic whites $(\mathrm{p}<0.001)$. Multivariate predictors of NID D M by multiple logistic regression analysis included increased age, BM I, WH R, fasting insulin and impaired glucose tolerance and decreased insulin secretion. The strongest independent predictors of NIDDM were high fasting insulin and decreased insulin secretion. These risk factors predicted NID D M equally well in high and low-risk populations. [Diabetologia (1997) 40: 62-66]

Keywords Mexican A mericans, insulin, obesity, NIDDM.
Numerous studies have shown that M exican A mericans have an increased prevalence [1-4] and incidence [5] of non-insulin-dependent diabetes mellitus (NID D M ) relative to non- $\mathrm{H}$ ispanic whites. The M exican A merican population is characterized by increased adiposity $[1-4,6]$, a more centralized distribution of body fat $[6,7]$, hyperinsulinaemia [8-10] and insulin resistance $[11,12]$.

R eceived: 16 J uly 1995 and in revised form: 17 September 1996

Corresponding author: Dr. S. Haffner, D epartment of Medicine, Division of Clinical E pidemiology, U niversity of Texas $\mathrm{H}$ ealth Science Center at San A ntonio, 7703 Floyd C url D rive, San A ntonio, Texas 78284-7873, U SA

A bbreviations: NID D M, N on-insulin-dependent diabetes mellitus; W HO, World H ealth Organization.
Metabolic factors have been shown to be important risk factors for the development of NIDDM. Both insulin resistance $[13,14]$ and hyperinsulinaemia $[13,15-19]$ have been shown to predict NID D M . Likewise, decreased insulin secretion in response to various stimuli may predict NIDDM. A low acute insulin response has been found to predict NID D M in Pima Indians [13], but not in children of two Caucasian diabetic parents [14]. A low 30-min increment in insulin relative to the 30 -min increment in glucose $\left(\Delta \mathrm{I}_{30} / \Delta \mathrm{G}_{30}\right)$ during an oral glucose tolerance test predicts conversion to NID D M, especially in subjects with impaired glucose tolerance [20-23]. A low insulin response $60 \mathrm{~min}$ after an intravenous glucose challenge also predicted NIDDM $[24,25]$. A low 2-h insulin in response to an oral glucose load also 
predicts conversion to NIDDM in impaired glucose tolerance subjects $[17,18]$. We have recently shown that both increased fasting insulin (a proxy for insulin resistance) and decreased $\Delta \mathrm{I}_{30} / \Delta \mathrm{G}_{30}$ (a proxy for decreased insulin secretion) predict the development of NIDDM in M exican A mericans [23].

Weir [26] has suggested that risk factors for NIDDM may differ in different populations. O bese subjects with a family history of diabetesare characterized by insulin resistance [27,28], while lean Caucasian subjects with a family history of diabetes may be characterized by decreased insulin secretion [29]. We thus examined whether risk factors for the development of NIDDM might differ in M exican A mericans (a highrisk population for NIDD M ) and non-H ispanic whites (a low-risk population for NIDDM). M ost previous studies of metabolic risk factors for NIDDM have been in high-risk populations [13-18, 23] with a few exceptions [19, 21, 24, 25]. Previous studies in high-risk populations ( which are generally obese and characterized by insulin resistance) have generally emphasized increased insulin resistance as a predictor of NID D M while studies in low-risk populations have often emphasized decreased insulin secretion. In a few cases such as in Swedish subjects both low insulin secretion and insulin resistance predicted the development of NIDDM $[24,25]$. H owever, no study has previously compared risk factorsfor the development of NID D M in high and low-risk populations.

\section{Subjects and methods}

The San A ntonio H eart Study is a population-based study of diabetes and cardiovascular disease in M exican A mericans and non-H ispanic whites. From 1979 to 1982 (Phase I) and from 1984 to 1988 (Phase II), we randomly selected households from low-income (barrio), middle income (transitional), and high income (suburban) census tracts in San A ntonio [1, 8]. M exican A mericans were defined as individuals whose ancestry and cultural traditions are derived from a M exican national origin [30]. This study was approved by the I nstitutional R eview B oard of the U niversity of Texas H ealth Science Center at San A ntonio. A II subjects gave informed consent.

B eginning in 0 ctober 1990, we began a 7 to 8-year followup of the Phase II cohort [23]. The results in this report are based on risk factors for the development of NIDDM in the first four of six census tracts (one upper, two low income, and one middle income) of the Phase II cohort. Subjects with diabetes at the baseline examination are excluded from the analyses presented in this report.

A the baseline and follow-up of the Phase II cohort, blood specimens were obtained after a 12 to 14 -h fast for determination of serum insulin and plasma glucose concentrations. Plasma glucose was determined by a glucose oxidase method. We measured serum insulin with a solid phase radioimmunoassay (D iagnostic Products Corporation, L os A ngeles, Calif., U SA ) which shows a relatively high degree of cross reactivity with proinsulin (about 70 to $100 \%$ ) [10]. A t Phase II baseline and follow-up, a 75-g glucose equivalent load (Koladex or O rangedex, Custom L aboratories, B altimore, M D, USA ) was administered and blood specimens were obtained $2 \mathrm{~h}$ later for plasma glucose and serum insulin concentrations. Diabetes and impaired glucose tolerance were diagnosed according to World Health O rganization (WHO) criteria [31]. Subjects who did not meet WHO plasma glucose criteria, but who were under treatment with oral antidiabetic agents or insulin were considered to have diabetes. Subjects on diet therapy or oral antihyperglycaemic therapy were considered to have NID D M . A dditionally, subjects on insulin therapy who were obese (body mass index $\geq 30 \mathrm{~kg} / \mathrm{m}^{2}$ ) and with an onset of diabetes greater than 40 years were also considered to have NIDDM. Other subjects taking insulin were considered to have possible insulin-dependent diabetes and were excluded from this report.

A nthropometric measurements (height, weight and waist and hip circumference) were made after participants had removed their shoes and upper garments and donned an examining gown [7]. B ody mass index was calculated as weight in kilograms divided by height in meters squared. Waist circumference was measured at the level of the umbilicus and hip circumference at the level of the greater trochanter. The waistto-hip ratio was used as a measure of upper body adiposity.

\section{Statistical analysis}

Statistical analyses were performed using the SA S statistical package (version 6.09). Statistical analyses included chisquared test (Table 1 ), M antel $\mathrm{H}$ aenszel odds ratio (Table 1 ), the $B$ reslow- $D$ ay test of heterogeneity (Table 1 ) and multiple logistic regression analyses (Tables 2 and 3). The Breslow$D$ ay test of heterogeneity is a test of statistical interaction. We also tested for statistical interaction (ethnicity $\times$ other risk factors such as fasting insulin) in multiple logistic regression analyses. N one of these interaction terms was significant $(p>0.05)$. Multiple logistic regression analyses were performed using both dichotomous predictor variables (above and below the median for the independent variables) and continuous independent variables. $B$ oth of these approaches yielded similar results. Therefore, the statistically more powerful continuous independent variables (except for impaired vs normal glucose tolerance) were used in multiple logistic regression analyses. The dependent variable in multiple logistic regression analyses was the development of NID D M. This report emphasizes fasting insulin as a measure of insulin resistance [32,33] and the ratio of the 30 min change in insulin to the 30 min change in glucose $\left(\Delta \mathrm{I}_{30} / \Delta \mathrm{G}_{30}\right)$ [34] during the oral glucose tolerance test as a measure of insulin secretion. We also tested $\Delta \mathrm{I}_{30}$ and $\Delta \mathrm{G}_{30}$ as separate independent variables in multiple logistic regression analyses (similar to Tables 2 and 3 ) and results were similar to those obtained with $\Delta \mathrm{I}_{30} / \Delta \mathrm{G}_{30}$ as a ratio. 0 nly the latter is presented in this report.

\section{Results}

The mean age was $43.5 \pm 0.3$ years and the mean body mass index was $28.0 \pm 0.3 \mathrm{~kg} / \mathrm{m}^{2}$. Table 1 shows the incidence of diabetes by ethnicity and selected variables. N one of the tests for heterogeneity was statistically significant suggesting that the effect of risk factors on the risk of developing diabetes is similar among subjects with high and low-levels of risk factors (e.g. obese vs lean).

Table 2 shows the results of multiple logistic regression analyses (separately for each ethnic group) 
Table 1. Incidence of NIDD M by ethnicity and selected variables

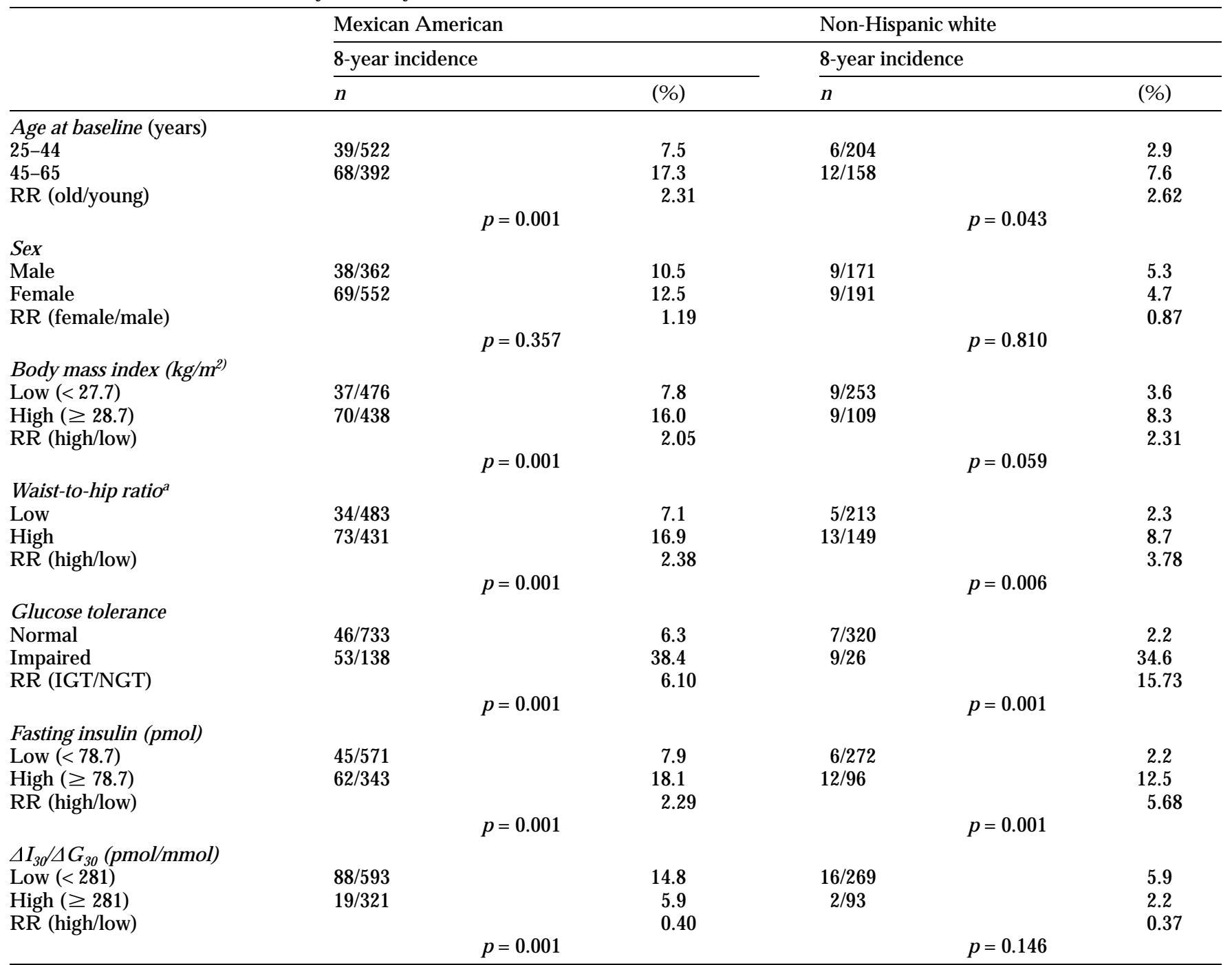

$\mathrm{R} R$, $\mathrm{R}$ elative risk; $\Delta \mathrm{I}_{30}$, change in insulin over first $30 \mathrm{~min}$ of a glucose tolerance test; $\Delta \mathrm{G}_{30}$, change in glucose over first $30 \mathrm{~min}$ of an oral glucose tolerance test
N ote: B reslow D ay test used to compute heterogeneity ${ }^{\text {a }}$ Cutoff point for women: 0.825; men: 0.938
Table 2. Multiple logistic regression analyses with the development of NIDDM as a dependent variable

\begin{tabular}{llllll}
\hline Variable & \multicolumn{2}{l}{ M exican A mericans } & & non-H ispanic whites \\
\cline { 2 - 3 } & Odds ratio & $\mathrm{p}$-value & & Odds ratio & $\mathrm{p}$-value \\
\hline Ln fasting insulin & 2.81 & $<0.001$ & & 5.12 & $<0.001$ \\
$\mathrm{Ln} \Delta \mathrm{I}_{30} / \Delta \mathrm{G}_{30}$ & 0.265 & $<0.001$ & & 0.440 & 0.040
\end{tabular}

A ge, gender, body mass index, waist-to-hip ratio and impaired glucose tolerance vs normal glucose tolerance were also included in the regression model.

$\Delta \mathrm{I}_{30} / \Delta \mathrm{G}_{30}$, Change in insulin to change in glucose over first 30 min of a glucose tolerance test

with the development of NIDDM as the dependent variable and fasting insulin and $\Delta \mathrm{I}_{30} / \Delta \mathrm{G}_{30}$ as independent variables. (In these models, age, body mass index, waist to hip ratio, gender and impaired glucose tolerance vs normal glucose tolerance were also included but are not shown in Table 2.) In M exican A mericans and non- $\mathrm{H}$ ispanic whites, both high fasting insulin and low $\Delta \mathrm{I}_{30} / \Delta \mathrm{G}_{30}$ predicted conversion to NIDDM. Fasting insulin was stronger in non-Hispanic whites and $\Delta \mathrm{I}_{30} / \Delta \mathrm{G}_{30}$ in Mexican A mericans. H owever, the interaction terms (ethnicity $\times$ fasting insulin and ethnicity $\times \Delta \mathrm{I}_{30} / \Delta \mathrm{G}_{30}$ ) were not statistically significant when the ethnic groups were pooled and an interaction term included in the model.

Table 3 presents a multiple logistic regression analyses in which the parameter estimates for all independent variables are shown. A ge, M exican A merican ethnicity, body mass index, waist to hip ratio, fasting insulin and impaired glucose tolerance were significantly positively related to NIDDM. A low $\Delta \mathrm{I}_{30} / \Delta \mathrm{G}_{30}$ was also significantly related to NIDDM. $G$ ender was not significantly related to NIDDM . 
Table 3. M ultiple logistic regression analyses with the development of NID D M as a dependent variable

\begin{tabular}{|c|c|c|c|c|c|c|}
\hline Variable & $\mathrm{B}$ & SE (B) & O dds ratio & $95 \%$ Confidence interval & $p$-value & Chi square \\
\hline A ge (years) & 0.215 & 0.109 & 1.24 & $1.002,1.535$ & 0.048 & 3.90 \\
\hline $\mathrm{G}$ ender (male/female) & 0.445 & 0.276 & 1.56 & $0.909,2.677$ & 0.107 & 2.60 \\
\hline E thnic ( M A / N HW) & 0.1207 & 0.3086 & 1.48 & $1.12,3.76$ & 0.019 & 5.45 \\
\hline Waist/hip ratio & 0.389 & 0.154 & 1.48 & $1.09,1.99$ & 0.011 & 6.45 \\
\hline Ln fasting insulin & 1.420 & 0.172 & 3.29 & $2.35,4.63$ & $<0.001$ & 46.3 \\
\hline$\Delta \mathrm{I}_{30} / \Delta \mathrm{G}_{30}$ & -1.12 & 0.174 & 0.322 & $0.219,0.476$ & $<0.001$ & 32.3 \\
\hline
\end{tabular}

$\mathrm{M} \mathrm{A}, \mathrm{M}$ exican A merican; $\mathrm{NHW}$, non-H ispanic white; $\Delta \mathrm{I}_{30} / \Delta \mathrm{G}_{30}$, change in insulin to change in glucose over the first 30 min of an oral glucose tolerance test

\section{Discussion}

We show that a similar pattern of risk factors for NIDDM operates in both high-risk populations for NIDDM characterized by obesity and insulin resistance and also in low-risk populations for NIDDM. In both M exican A mericans and non- $\mathrm{H}$ ispanic whites, increased fasting insulin significantly predicted the development of NID D M . A low $\Delta \mathrm{I}_{30} / \Delta \mathrm{G}_{30}$ representing decreased insulin secretion in response to oral glucose predicted NIDDM significantly in Mexican A mericans but not in non- $\mathrm{H}$ ispanic whites. $\mathrm{H}$ owever, the point estimate for the risk ratio for low $\Delta \mathrm{I}_{30} / \Delta \mathrm{G}_{30}$ (Table 1) was similar in the two ethnic groups, suggesting that the lack of association in non- $\mathrm{H}$ ispanic whites may be due to low statistical power. M oreover, when both ethnic groups were combined, and the interaction term for $\Delta \mathrm{I}_{30} / \Delta \mathrm{G}_{30} \times$ ethnicity was tested, this term was not statistically significant.

In previous reports, especially in non-diabetic relatives of subjects with NID D M , there has been controversy about which defect (decreased insulin secretion or insulin resistance) is more important [26-29, 35, 36]. O ur data suggest that both are important in the aetiology of NIDDM in both high and low-risk populations for NIDDM. Increased fasting insulin was a stronger predictor in terms of relative risk in non-H ispanic whites than in M exican A mericans which was contrary to our initial hypothesis that fasting insulin would be stronger in M exican A mericans. H owever, the $B$ reslow-D ay test for heterogeneity was not statistically significant $(p=0.11)$. These data are compatible with a recent report showing defects in both insulin secretion and resistance in identical twins discordant for NIDDM [36]. In previous studies, a low acute insulin response predicted the development of NIDDM in obese Pima Indians [13], but not in children of diabetic Caucasian parents [14]. In the Pima study, insulin secretion was a much weaker predictor of NIDDM than was decreased insulin sensitivity [13]. In two Swedish studies, both decreased insulin secretion (as judged by the 60 -min insulin response to an intravenous glucose challenge) and insulin sensitivity (as judged by fasting insulin level) predicted the development of NIDD M $[24,25]$.
Relatively few studies have directly compared fasting insulin with insulin resistance in their relative ability to predict the incidence of NIDD M. L ow insulin sensitivity (at the 10th percentile compared to the 90 th percentile) was associated with a 30 -fold relative risk of NIDDM, whereas high fasting insulin (at the 90th percentile compared to the 10th percentile) was associated with a 15 -fold relative risk of NIDDM in Pima Indians [13].

In the present report, insulin was measured with an assay that cross-reacts with proinsulin. Several studies have shown that proinsulin is disproportionately elevated in subjects with NID DM [10, 37-41]. The ratio of fasting proinsulin/fasting insulin, however, is only minimally elevated in subjects with impaired glucose tolerance in some studies [10, 39] and not at all in others [40]. A the time of the baseline survey (1984-1988), specific insulin assays were not available. However, the ratio of fasting proinsulin/ specific insulin in M exican A mericans with impaired glucose tolerance (measured at the follow-up examination) [10] is only slightly higher than in Mexican A merican subjects with normal glucose tolerance ( 0.09 vs 0.07 , respectively), but still very low, and thus unlikely to confound our measurement of insulin at baseline. A dditionally, non-diabetic Mexican A mericans have similar fasting proinsulin/insulin ratios to non-diabetic non-Hispanic whites [10].

In conclusion, we have shown that risk factors for NIDDM are similar in different populations having differing risks of NIDDM suggesting that for most subjects, similar pathophysiologic mechanisms may apply, although clearly the genetic basis may differ. In future studies, more sophisticated measures of insulin resistance (e.g. hyperinsulinaemic euglycaemic clamp or frequently sampled intravenous glucose tolerance test) and secretion (e.g. acute insulin response) should be performed, although these tests are expensive and thus might be restricted to highrisk subjects such as those with impaired glucose tolerance.

A cknowledgements. This work was supported by grants R 01 HI24799 and R 37 HL 36820 from the National Heart, L ung and Blood Institute. 


\section{References}

1. Stern M P, R osenthal M , H affner SM , H azuda H P, Franco LJ (1984) Sex differences in the effects of sociocultural status in diabetes and cardiovascular risk factors in M exican A mericans: The San A ntonio $\mathrm{H}$ eart Study. A m J E pidemiol 120: 834-851

2. $\mathrm{H}$ anis $\mathrm{CL}$, Ferrell RE, Barton $\mathrm{SA}$ et al. (1983) Diabetes among M exican A mericans in Starr County, Texas. A m J E pidemiol 118: 659-672

3. Samet J M , Coultas D B , H oward CA , Skipper BJ, H anis CL (1988) Diabetes, gall bladder disease, obesity, and hypertension among $\mathrm{H}$ ispanics in N ew M exico. A m J E pidemiol 128: 1302-1311

4. H amman R F, M arshall JA, B axter J et al. (1989) M ethods and prevalence of non-insulin dependent diabetes mellitus in a biethnic Colorado population: The San Luis Valley Diabetes Study. A m J E pidemiol 129: 295-311

5. H affner SM, H azuda H P, M itchell BD, Patterson JK, Stern M P (1991) Increased incidence of Type II diabetes mellitus in M exican A mericans. Diabetes Care 14: 102-108

6. Joos SK, M ueller WH, H anis CL, Schull WJ (1984) D iabetes A lert Study: weight history and upper body obesity in diabetic and nondiabetic M exican A merican adults. A nn H uman B iol 11: 167-171

7. $\mathrm{H}$ affner SM, Stern M P, H azuda H P, Pugh JA , Patterson J K, M alina $\mathrm{R}$ (1986) U pper body and centralized adiposity in M exican A mericans and non-Hispanic whites: relationship to body mass index and other behavioral and demographic variables. Int I 0 besity 10 : 493-502

8. H affner SM, Stern M P, H azuda H P, Pugh JA, Patterson J K (1986) $\mathrm{H}$ yperinsulinemia in a population of high risk for non-insulin dependent diabetes mellitus. N Engl J M ed 315: 220-224

9. B oyko E J, K eane G M , M arshall JA , H amman R F (1991) H igher insulin and $\mathrm{C}$-peptide concentrations in $\mathrm{H}$ ispanic population at high risk for NIDDM : San Luis Valley Diabetes Study. Diabetes 40: 509-515

10. Haffner SM, Bowsher RR, Mykkänen L et al. (1994) Proinsulin and specific insulin concentrations in high and low risk populations for non-insulin dependent diabetes mellitus. Diabetes 43: 14901493

11. H affner SM, Stern M P, D unn J F, M obley M, B lackwell J, B ergman R N (1994) Diminished insulin sensitivity and increased insulin response in non-obese, non-diabetic Mexican A mericans. M etabolism 39: 842-847

12. H affner SM, D 'A gostino J $r$ R, Saad M F et al. (1996) Increased insulin resistance and insulin secretion in non-diabetic $A$ frican $A$ mericans and $\mathrm{H}$ ispanics compared with non-H ispanic whites: The Insulin R esistance A therosclerosis Study. D iabetes 45: 742-748

13. Lillioja S, M ott D M, Spraul M, et al. (1993) Insulin resistance and insulin secretory dysfunction as precursors of non-insulin dependent diabetes mellitus. Prospective studies of Pima Indians. N E ngl J Med 329: 1988-1992

14. Warram JK, Martin BC, Krolewski NS, Soeldner JS, Kahn CR (1990) Slow glucose removal rate and hyperinsulinemia precede the development of type II diabetes in the offspring of diabetic parents. A nn Intern M ed 113: 909-915

15. $\mathrm{H}$ affner SM, Stern M P, M itchell BD, Hazuda H P, Patterson J K (1990) Incidence of type II diabetes in M exican A mericans predicted by testing insulin and glucose levels, obesity, and body fat distribution. Diabetes 39: 283-288

16. Bergstrom RW, Newell-M orris $L L$, L eonetti $D L$, Shuman $W P$, Wahl PW, Fujimoto WY (1990) A ssociation of elevated fasting Cpeptide levels and increased intra-abdominal fat distribution with development of NID D M in Japanese A merican men. Diabetes 39 : 104-111

17. Sicree R A , Zimmet PZ, K ing H O, Coventry J S (1987) Plasma insulin response among $N$ auruans: prediction of deterioration in glucose tolerance over 6 years. D iabetes 36: 179-186

18. Saad R M, K nowler W C, Pettitt DJ, N elson R G, M ott D M, B ennett $\mathrm{PH}$ (1988) The natural history of impaired glucose tolerance in the Pima Indians. N Engl J Med 319: 1500-1506

19. Charles MA, Fontbonne A, Thibult N, Warnet J M, R osselin GE, E schwege G (1991) Risk factors for NID D M in white populations. Paris Prospective Study. D iabetes 40: 796-799

20. Effendic $S$, L uft $R$, Wajngot $A$ (1984) A spects of the pathogenesis of type II diabetes. Endoc R ev 5: 395-410
21. Kadowaki T, M iyake $Y, H$ agura $R$ et al. (1984) R isk factors for worsening to diabetes in subjects with impaired glucose tolerance. D iabetologia 26: 44-49

22. Chen KW, B oyko EJ, B ergstrom RW, L eonetti D L, N ewell-M orris L, Wahl PW, Fujimoto WY (1995) E arlier appearance of impaired insulin secretion than of visceral adiposity in the pathogenesis of NID D M : 5-year follow-up of initially non-diabetic Japanese A merican men. D iabetes Care 18: 747-753

23. $H$ affner SM, M iettinen H, G askill SP, Stern M P (1995) D ecreased insulin secretion and increased insulin resistance are independently related to the 7-year risk of non-insulin dependent diabetes mellitus in M exican A mericans. D iabetes 44: 1386-1391

24. Skarfors ET, Selinus KI, Lithell H O (1991) R isk factors for developing non-insulin dependent diabetes: a 10-year follow-up of men in U ppsala. B M J 303: 755-760

25. L undgren $H$, B engtsson $C$, B lohme $G$, L apidus $L$, Waldenström J (1990) Fasting serum insulin concentrations and early insulin response as risk determinants for developing diabetes. D iabet $M$ ed 7: 407-413

26. Weir GC (1995) Which comes first in non-insulin dependent diabetes mellitus: insulin resistance or B-cell failure? B oth came first. JA M A 273: 1878-1879 (editorial).

27. Gulli G, Ferrannini E, Stern M, H affner S, D eFronzo R A (1992) The metabolic profile of NID D M is fully established in glucose-tolerant offsprings of two M exican A merican NIDDM parents. Diabetes 41: 1575-1586

28. E riksson J, Franssila-K allunki A, Ekstrand A et al. (1989) E arly metabolic defects in persons at increased risk for non-insulin dependent diabetes mellitus. N Engl J M ed 321: 337-343.

29. Pimenta W, Korytkowski M, M itrakou A et al. (1995) Pancreatic $\beta$ cell dysfunction as the primary genetic lesion in NID D M. E vidence from studies in normal glucose tolerant individuals with a first-degree NIDDM relative. JA M A 273: 1855-1861

30. H azuda H P, Comeaux PJ, Stern M P, H affner SM, E ifler CW, R osenthal M (1980) A comparison of three indicators for identifying Mexican A mericans in epidemiologic research: methodological findings from the San A ntonio H eart Study. A m J E pidemiol 123: 96-112

31. World $\mathrm{H}$ ealth O rganization Expert Committee on D iabetes $\mathrm{M}$ ellitus (1985) Second R eport. G eneva, Switzerland. World H ealth O rganization Technical R eport Series N 0.727

32. Hollenbeck CB, Chen N, Chen Y D, R eaven G M (1984) R elationship between the plasma insulin response to oral glucose and insulin stimulated glucose utilization in normal subjects. Diabetes 33: 460-463

33. Saad M F, A nderson R L, L aws A et al. (1994) for the IR A S. A comparison between the minimal model and the glucose clamp in the assessment of insulin sensitivity across the spectrum of glucose tolerance. D iabetes 43: 1114-1121

34. Philips DI, Clark PM, H ales CN , O smond C (1994) U nderstanding oral glucose tolerance: comparison of glucose and insulin measurements during the oral glucose tolerance test with specific measurements of insulin resistance and secretion. D iabet M ed 11: 286-292

35. O'R ahilly SP, N ugent $Z$, R udenski A S et al. (1986) B eta cell dysfunction, rather than insulin insensitivity is the primary defect in familial type 2 diabetes. $L$ ancet 2: 361-364

36. Vaag $A, H$ enriksen JE, Madsbad S, Holm N, Beck-Nielsen $H$ (1995) Insulin secretion, insulin action and hepatic glucose production in identical twins for non-insulin-dependent diabetes mellitus. J Clin Invest 95: 690-698

37. Temple R C, Carrington CA, Luzio SD et al. (1989) Insulin deficiency in non-insulin dependent diabetes. $L$ ancet 1: 293-295

38. R eaven G M, Chen Y D I, H ollenbeck CB, Sheu WH H, O strega D, Polonsky K S (1993) Plasma insulin, C-peptide and proinsulin concentrations in obese and non-obese individuals with varying degrees of glucose tolerance. J Clin E ndocrinol M etab 76: 44-48

39. Yoshioka N, Kuzuya T, M atsuda A, Taniguchi M, I wamoto $Y$ (1988) Serum proinsulin levels at fasting and after oral glucose load in patients with type 2 (non-insulin-dependent) diabetes mellitus. Diabetologia 31: 355-360

40. Saad M F, K ahn SE, N elson R G, et al. (1990) D isproportionately elevated proinsulin in Pima Indians with non-insulin dependent diabetes mellitus. J Clin E ndocrinol M etab 70: 1247-1253

41. Porte D (1991) Banting Lecture 1990. $\beta$ cells in type II diabetes mellitus. D iabetes 40: 166-180 